\title{
Erratum to: A Systematic Review of HIV and STI Behavior Change Interventions for Female Sex Workers in the United States
}

\author{
Neetu Abad ${ }^{1}$ - Brittney N. Baack ${ }^{2}$ Ann O'Leary ${ }^{2}$ 'Yuko Mizuno ${ }^{2}$ \\ Jeffrey H. Herbst ${ }^{3}$. Cynthia M. Lyles ${ }^{2}$
}

Published online: 10 September 2015

(C) Springer Science+Business Media New York 2015

\section{Erratum to: AIDS Behav DOI 10.1007/s10461-015-1013-2}

The original version of this article unfortunately contained the following errors. The errors have been corrected with this erratum.

1. The following CDC disclaimer needs to be included:

"The findings and conclusions in this report are those of the authors and do not necessarily represent the official position of the US Centers for Disease Control and Prevention."

2. The author affiliation of Jeffrey H. Herbst at the time this work was conducted is the Division of HIV/AIDS Prevention at the Centers for Disease Control and Prevention in Atlanta, GA. Dr. Herbst is now affiliated with the Division of Violence Prevention at the Centers for Disease Control and Prevention in Atlanta, GA.

3. The hyperlink for the risk reduction review methods reported in the first paragraph of the methods section

The online version of the original article can be found under doi:10.1007/s10461-015-1013-2.

Neetu Abad

vjx3@cdc.gov

1 Division of STD Prevention, NCHHSTP, Centers for Disease, Control and Prevention, 1600 Clifton Road NE, Mailstop E-44, Atlanta, GA 30333, USA

2 Division of HIV/AIDS Prevention, NCHHSTP, Centers for Disease Control and Prevention, Atlanta, GA, USA

3 Division of HIV/AIDS Prevention, NCIPC, Centers for Disease Control and Prevention, Atlanta, GA, USA and the 10th paragraph of the discussion section should be replaced with:

http://www.cdc.gov/hiv/dhap/prb/prs/efficacy/rr/ criteria/

4. Moher (2009) should be included in the list of citations:

Moher D, Liberati A, Tetzlaff, J Altman, D, PRISMA Group. Preferred reporting items for systematic reviews and meta-analyses: the PRISMA statement. PLOS Med. 2009;6(7):e1000097. doi:10. 1371/journal.pmed.1000097.

5. The word "little" is missing from paragraph 4 , line 7 in the discussion section.

6. Table 1, Sample $>50 \%$ FSW $(\mathrm{k}=11)$, Bowser, Target population:

Incorrect: Targeted drug-using FSW or color most likely to fail in regular drug tx

Correct: Targeted drug-using women of color most likely to fail in regular drug tx

Incorrect: Included $100 \%$ FSW

Correct: NR

7. Table 3, Target:

Incorrect: Mental Health Treatment: 1 (8)

Correct: Mental Health treatment: 1 (20)

8 Table 3, $>50 \%$ FSW:

Incorrect: African-American Feminism: 1 (9)

Correct: African-American Feminism: 1 (8) 